\title{
Cross sectional survey analysis of eye donation awareness among medical, dental and nursing students in a teaching hospital/tertiary hospital
}

\author{
Siddharam Janti ${ }^{1, *}$, Ananya Aila ${ }^{2}$, Kiruthika.$S^{3}$, Stephen Sudhakar $^{4}$ \\ ${ }^{1}$ Associate Professor, ${ }^{2}$ Post Graduate, ${ }^{3}$ Senior Resident, ${ }^{4}$ Professor and HOD, Dept. of Ophthalmology, Chettinad Health and \\ Research Institute, Kelambakkam, Tamil Nadu, India
}

*Corresponding Author:

Email: drsiddharam@gmail.com

\begin{abstract}
Introduction: Visual rehabilitation by corneal transplantation remains the only treatment modality for treatable corneal blindness. Unfortunately the demand of the donated cornea remains high in comparison to its procurement. As these target groups will be future health care providers thus it is important that they know the intricacies of corneal donation. These groups will create awareness among the general public, thereby significantly increasing the corneal donation rate.

Objectives: To study the awareness and knowledge among medical, dental and nursing students towards eye donation in a medical college/Tertiary hospital

Materials and Methods: A cross-sectional study was conducted among 100 medical, 100 nursing and 100 dental students studying final year of their respective courses in Chettinad Health and Research Institute, Chennai.

Results: There was statistically significance in knowledge between the medical and all other groups showing that medical students are more aware about the practice of corneal donation.(p value: 0.0000001$)$. Overall the awareness about the existence of practice of eye donation was only $57 \%$ among the study groups. Only $33.3 \%$ of study populations were willing to donate their eyes and $36 \%$ of study populations were willing to donate their relative's eyes. $67.3 \%$ of the students required their family's consent and approval for corneal donation. $58.6 \%$ of the students knew that eyes cannot be donated by a living person and also fact that a living person can only pledge for eye donation.

$54 \%$ knew that eyeball should be removed within six hours after death. Only $49 \%$ of the study population knew the name of nearest eye bank and only $24.6 \%$ of study population knew how long the donated eyes can be stored before transplantation. Overall, the awareness and knowledge of medical students was better than nursing and dental students in all the above aspects ( $p$ value: 0.0000001 ) but the levels of motivation were low in all the study groups (p value: 0.006).

Conclusion: The result of this study concluded that medical students were more knowledgeable about various intricacies associated with corneal donation than other two study groups (p value: 0.0000001 ) which was statistically significant. There was no statistical significance seen in motivation levels of all study groups ( $\mathrm{p}$ value: 0.06 ). This study was undertaken to assess the depth of awareness and knowledge among the study groups. These groups are targeted as they are future care providers giving us an idea about targeting motivation and awareness programmes among these groups.
\end{abstract}

Keywords: Corneal donation, Dental, Medical and nursing students, Awareness, Knowledge.

\section{Introduction}

According to the World Health Organization, corneal diseases stand among the major causes of vision loss and blindness in the developing countries ${ }^{1}$. According to the National Programme for Control of Blindness (NPCB) estimates, there are currently 120,000 , corneal blind persons in India. ${ }^{2}$ According to this estimate there is an addition of 25,000-30,000 corneal blindness cases every year in the country, out of which $40 \%$ can be cured by corneal transplantation. ${ }^{1,2}$ Only $34 \%$ of corneas are donated every year which is just sufficient to correct only $28 \%$ of total blind persons every year. ${ }^{3}$ There, currently exists a large gap between the demand and supply of the donated cornea. This study is undertaken to analyze the depth of knowledge and awareness among various groups of students in a tertiary care hospital. These groups are specifically targeted as these students are future care providers who can influence the thinking of general public. This gives an insight to educate these groups as these groups closely work with tertiary hospitals. Tertiary care hospitals with ICUs and trauma centers have high morbidity rates. Therefore, cornea procurement rates can be made higher by targeting and these study groups in various tertiary health care centers.

\section{Materials and Methods}

A cross-sectional questionnaire based study containing 25 questions was done among 100 Medical, 100 Dental and 100 Nursing students in a teaching hospital/tertiary centre who were pursing final year of their respective courses. The purpose of this study was explained to all the study groups and all of these students are subjected to this questionnaire after getting verbal consent. Students were asked to write answers for the questions given in the questionnaire. The data was collected and entered in a MS office excel sheet and was statistically analyzed by SPSS. Chi square test was used for analysis. Statistical significance of less than 0.05 was considered as significance.

\section{Results}

There were 300 students involved in these study100 students from each of Medical, dental and nursing 
branches pursuing their final year of respective courses. The questionnaire tested three aspects 1) Source of information for the idea of donation. 2) Awareness of the subject about corneal donation 3) Knowledge of the subject about eye bank and its intricacies which were statistically analyzed.

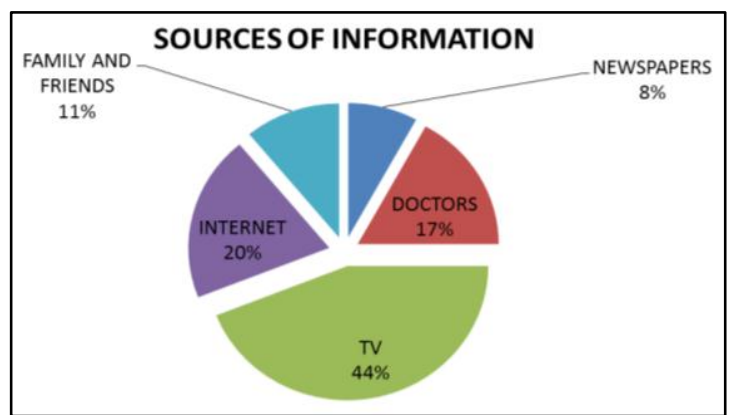

Fig. 1: Shows the sources of information from where students got their ideas about corneal donation

According to the students, Electronic media (such as TV and internet) (64\%) provided most of their ideas about corneal donation among study groups Other sources of information included by Doctors (17\%), Family and friends $(11 \%)$ and newspapers $(8 \%)$.

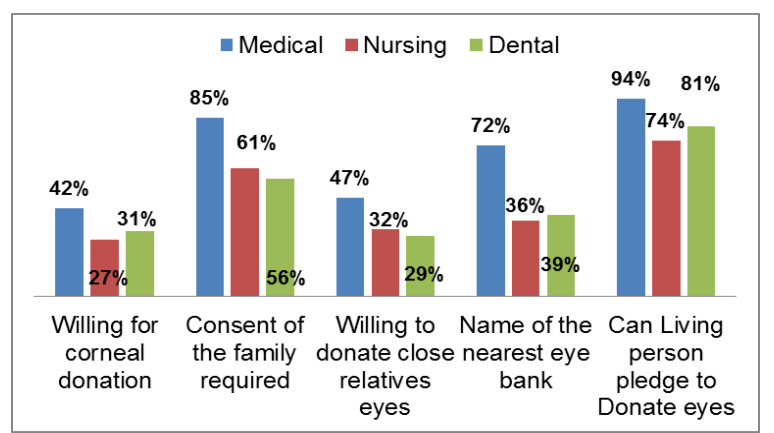

Fig. 2: Showing awareness about corneal donation

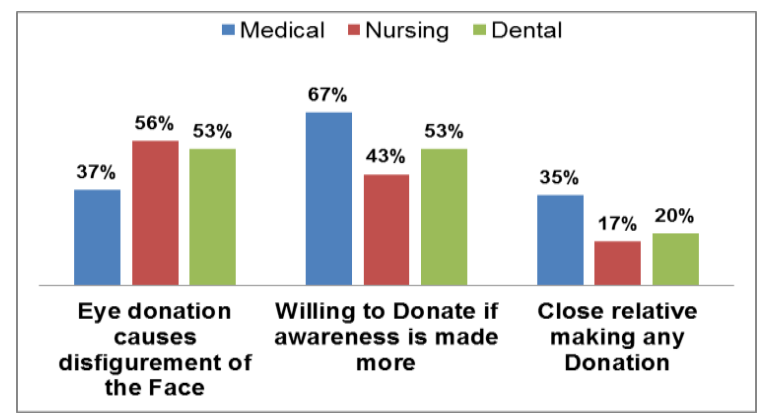

Fig. 3: Showing awareness about corneal donation

Fig. 2 and 3 showed the awareness of corneal donation among the study groups. Results are as follows:

1. Out of 300 students, only $42 \%$ of medical students, $27 \%$ of nursing students and $31 \%$ of dental students were willing for corneal donation showing low motivation levels ( $p$ value: 0.06 ) in all study groups.
2. Most of the students ( $85 \%$ of medical students, $61 \%$ of nursing students and $56 \%$ of dental students) needed their family consent for donation.

3. $47 \%$ of medical students, $32 \%$ of nursing students and $29 \%$ of dental students were willing to donate close relatives eyes.

4. Only $72 \%$ of medical students, $36 \%$ of nursing students and $39 \%$ of dental students knew the location of the nearest eye bank.

5. $94 \%$ of medical students, $74 \%$ of nursing students and $81 \%$ of nursing students knew that living people can pledge to donate eyes.

6. $37 \%$ of medical students, $56 \%$ of nursing students and $53 \%$ of dental students believe that eye donation causes disfigurement of face.

7. $67 \%$ of medical students, $43 \%$ of nursing students and $53 \%$ of dental students were willing to donate if the awareness was made more.

8. Only $35 \%$ of medical students, $17 \%$ of nursing students and $20 \%$ of dental students knew incidents of their relatives making corneal donation.

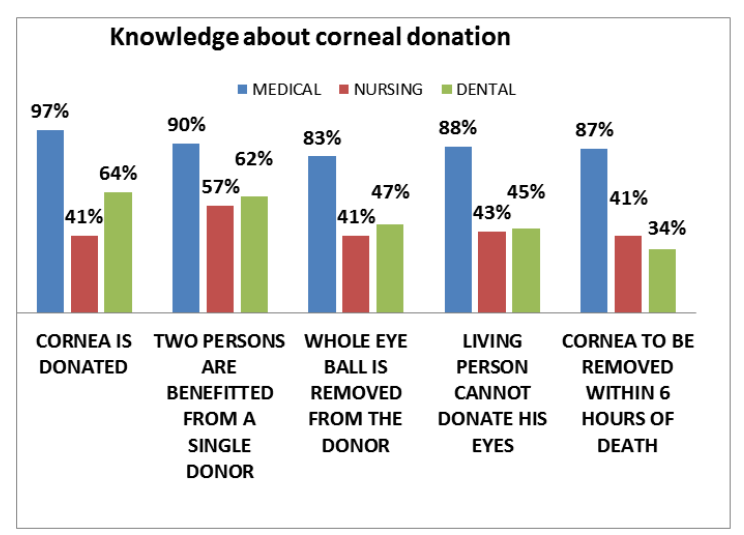

Fig. 4: Showing knowledge about corneal donation

Fig 4 showed knowledge of corneal donation among various study groups. The results are as follows:

1. Out of 300 students, $97 \%$ of medical students, $41 \%$ of nursing students and $64 \%$ of dental students knew that only cornea can currently be used for donation in the eye and corneal donation can restore vision.

2. $90 \%$ of medical students, $57 \%$ of nursing students and $62 \%$ of dental students knew that two persons would be benefitted from a single donor.

3. $83 \%$ of medical students, $41 \%$ of nursing students and $47 \%$ of dental students were aware of the fact that whole eyeball is removed from the donor.

4. $88 \%$ of medical students, $43 \%$ of nursing students and $45 \%$ of dental students knew that living persons cannot donate his eyes, but can only pledge for corneal donation.

5. $87 \%$ of medical students, $41 \%$ of nursing students and $34 \%$ of dental students were aware of the fact that cornea must be removed within 6 hours of death. 
6. $35 \%$ of medical students, $76 \%$ of nursing students and $74 \%$ of dental students believe that all the bind persons will be benefitted by corneal donation.

7. $23 \%$ of medical students, $67 \%$ of nursing students and $61 \%$ of dental students believe that all persons are eligible for eye donation after death.

8. Only $36 \%$ of medical students, $17 \%$ of nursing students and $21 \%$ of dental students knew about the intricacies and functioning of an eye bank.

Only $33.3 \%$ of study population was willing to donate their eyes and $67.3 \%$ of the students required their family's consent and approval for corneal donation.58.6\% of the students knew that eyes cannot be donated by a living person. $54 \%$ knew that eyeball should be removed within six hours after death. Only
$49 \%$ of the study population knew the name of nearest eye bank and only $24.6 \%$ of study population knew how long the donated eyes can be stored before transplantation. Overall the awareness and knowledge about the existence of practice of eye donation was only $67.3 \%$ among the study groups which was more in medical group (p value: 0.0000001) which were depicted in Table 2 to Table 6 . It was found that medical students were more aware about various aspects of corneal donation which was statistically significant but the motivation levels were very low in all target groups (p value: 0.06 ) which was depicted in Table 1.

Table 1: Showing overall willingness of study groups for corneal donation among the study groups

\begin{tabular}{|l|c|c|c|c|c|}
\hline Branch & Yes & No & chi square value & p value & Conclusion \\
\cline { 1 - 3 } Medical & 42 & 58 & & & \\
Nursing & 27 & 73 & 5.43 & 0.06 & $\begin{array}{c}\text { No significant association between the study } \\
\text { groups }\end{array}$ \\
\hline Dental & 31 & 69 & & 0.06 \\
\hline
\end{tabular}

Table 2: Showing over all knowledge about corneal donation among the study groups

\begin{tabular}{|l|c|c|c|c|}
\hline Branch & Correct answers & Wrong answers & chi square value & \multirow{2}{*}{ p value } \\
\hline Medical & 97 & 3 & 72 & \\
\cline { 1 - 3 } Nursing & 41 & 9 & & \multirow{2}{*}{0.0000001} \\
\hline
\end{tabular}

Table 3: Showing over all knowledge about entire eyeball being removed from the donor among the study groups

\begin{tabular}{|c|c|c|c|c|c|}
\hline Branch & Yes & No & $\begin{array}{c}\text { chi square } \\
\text { value }\end{array}$ & p value & Conclusion \\
\hline Medical & 83 & 13 & \multirow{3}{*}{42.1} & \multirow[b]{3}{*}{0.00001} & \multirow{3}{*}{$\begin{array}{c}\text { There is a statistically significant association } \\
\text { between branch and knowledge about entire } \\
\text { eyeball being removed from the donor. }\end{array}$} \\
\hline Nursing & 41 & 59 & & & \\
\hline Dental & 47 & 53 & & & \\
\hline
\end{tabular}

Table 4: Showing over all knowledge about corneal removal after death

\begin{tabular}{|c|c|c|c|c|c|}
\hline Branch & Yes & No & $\begin{array}{c}\text { chi square } \\
\text { value }\end{array}$ & p value & Conclusion \\
\hline Medical & 87 & 13 & \multirow{3}{*}{50.2} & \multirow[b]{3}{*}{0.00001} & \multirow{3}{*}{$\begin{array}{l}\text { There is a statistically significant association } \\
\text { between branch and knowledge about cornea has to } \\
\text { be removed after six hours of death. }\end{array}$} \\
\hline Nursing & 41 & 59 & & & \\
\hline Dental & 34 & 66 & & & \\
\hline
\end{tabular}

Table 5: Showing over all knowledge about all persons will be eligible for eye donation after death

\begin{tabular}{|c|c|c|c|c|c|}
\hline Branch & Yes & No & $\begin{array}{c}\text { chi square } \\
\text { value }\end{array}$ & p value & Conclusion \\
\hline Medical & 23 & 77 & \multirow{3}{*}{45.5} & \multirow[b]{3}{*}{0.0001} & \multirow{3}{*}{$\begin{array}{l}\text { There is a statistically significant association } \\
\text { between branch and knowledge about all persons } \\
\text { will be eligible for eye donation after death. }\end{array}$} \\
\hline Nursing & 67 & 33 & & & \\
\hline Dental & 61 & 39 & & & \\
\hline
\end{tabular}

Table 6: Showing over all knowledge about functioning of an eye bank

\begin{tabular}{|c|c|c|c|c|c|}
\hline Branch & Yes & No & chi square value & p value & Conclusion \\
\hline Medical & 36 & 64 & \multirow{3}{*}{10.8} & \multirow[b]{3}{*}{0.05} & \multirow{3}{*}{$\begin{array}{c}\text { There is a statistically significant association } \\
\text { between branch and knowledge about } \\
\text { functioning of eye bank }\end{array}$} \\
\hline Nursing & 17 & 83 & & & \\
\hline Dental & 21 & 79 & & & \\
\hline
\end{tabular}




\section{Discussion}

The burden of corneal blindness in a developing country like India is increasing day by day out of which almost $40 \%$ can be easily cured by transplantation. ${ }^{4}$ Various studies concluded that the major causes of treatable corneal blindness are trachoma, corneal ulceration, xerophthalmia due to vitamin A deficiency, ophthalmia neonatorum, leprosy and ocular trauma. These diseases can be easily treated by corneal transplantation Though the understanding of corneal anatomy and physiology especially with regard to corneal endothelium, introduction of microsurgical techniques and advances in corneal preservation, the use of corneal immune suppressive agents have increased the success rates of corneal transplantation, but lack of awareness and motivation among general public are creating hindrances in procurement of donated cornea. This study therefore was undertaken assess the depth of awareness and motivation among these groups who closely work with the tertiary hospital centers. These groups can be targeted and awareness created among them who in turn, can influence the general public. A similar study was conducted by Sanjeev Kumar et $\mathrm{al}^{5}$ in a medical college among medical, paramedical and nursing showed lack of awareness motivation among all the study groups. The present study demonstrated higher awareness levels among all the study groups compared to the above study. But the motivation levels remained almost the same. Similar awareness eye studies conducted by Rhimjhim Kumari et $\mathrm{al}^{6}$ in a medical college/teaching institute and Rucha Harish Gulhane et $\mathrm{al}^{7,8}$ among medical students showed low awareness and motivation among these students. A study by Vijay mahantesh et $\mathrm{al}^{9,10}$ among attenders of patients who were admitted in ICU, emergency department and outpatient departments showed many misconceptions about this noble act because of lack of awareness. Proper awareness among the health personnel can be undertaken to drive away all these misconceptions among the patient 's attenders and general public which can lead to better procurement of donated cornea and reduce the burden of blindness in a developing country like India.

\section{Conclusion}

This study showed low motivation levels among all the study groups and despite the fact that the medical students were more knowledgeable about corneal donation and its various aspect, it was quite saddening to see their unwillingness for corneal donation this study gives us an insight targeting various awareness programmes and increasing the levels of awareness among these groups. These groups closely work with tertiary health care centers where they can influence the thinking of general public visiting these centers. It is important to make these target groups aware about the burden of corneal blindness on a developing country like India. These groups can in turn influence the thinking of general public and motivate them to contribute to this noble cause.

\section{References}

1. Whitcher JP, Srinivasan M, Upadhyay MP. Corneal blindness: a global perspective. Bull World Health Organ 2001;79:214-21.

2. Dr. R. Jose, Present status of the National Programme for Control of Blindness in India; Community Eye Health Journal,2008,65:S103-105.

3. S Krishnaiah, V Kovai, R Nutheti, Bindiganavale, R Shamanna, R Thomas, Gullapalli N Rao. Awareness of eye donation in the rural population of India. Indian $J$ Ophthalmol 2004;52:1:73-78.9.

4. Dandona R, Dandona L. Corneal blindness in a southern Indian population: Need for health promotion strategies. $\mathrm{Br}$ J Ophthalmol 2003;87:133-137.

5. Kumar S, Shukla US, Agarwal P. Awareness and Knowledge on Eye Donation among Students at Bhopal. Natl J Community Med 2012;3(4):685-9.

6. Rimjhim Kumari.: Asian Journal of Biomedical and Pharmaceutical Sciences, 6(53), 2016, 37-38.

7. Rucha Harish Gulhane, Shubhangi Milind, SMBT institute of medical sciences and Research centre, Dhamangaon Ghoti; Nasik, Knowledge and awareness regarding eye donation among medical students, Scholars Journal of Applied Medical Sciences (SJAMS).

8. Manjunath S Nekar, Laxmikant Lokare, Sunil A Gokhale, Maneesha Godbole, S Y Mulkipatil,Awareness of eye donation among college students of Hubli city,Karnataka.International Journal of Biomedical Research 2012, Vol 3, No. 4, 201-204.

9. Vijayamahantesh. M. Bijapur, Vallabha K., Department of Ophthalmology, BLDEU's Shri B M Patil Medical College, Knowledge, Attitude and Practice Patterns Regarding Eye Donation, Eye Banking and Corneal Transplant in a Tertiary Care Hospital, JKIMSU, Vol. 4, No. 4, Oct-Dec 2015.

10. Dhaliwal U. Enhancing eye donation rates. Training students to be motivators. Indian J Ophthalmol 2002;50:209-12. 